\title{
Current use of contraceptive method among women in a middle-income developing country
}

This article was published in the following Dove Press journal:

Open Access Journal of Contraception

19 June 2010

Number of times this article has been viewed

\author{
Paul A Bourne' \\ Christopher AD Charles ${ }^{2,3}$ \\ Tazhmoye V Crawford ${ }^{4}$ \\ Maureen D Kerr-Campbell ${ }^{5}$ \\ Cynthia G Francis' \\ Neva South-Bourne' \\ 'Department of Community Health \\ and Psychiatry, Faculty of Medical \\ Sciences, The University of the West \\ Indies, Mona, Kingston, Jamaica; ${ }^{2}$ King \\ Graduate School, Monroe College, \\ Bronx, New York, USA; ${ }^{3}$ Center for \\ Victim Support, Harlem Hospital \\ Center, New York; ${ }^{4}$ Basic Medical \\ Sciences, Faculty of Medical Sciences, \\ ${ }^{5}$ Systems Development Unit, Main \\ Library, Faculty of Humanities and \\ Education, The University of the West \\ Indies, Mona, Jamaica
}

Correspondence: Paul Andrew Bourne Public Health Specialist, Department of Community Health and Psychiatry, Faculty of Medical Sciences, The University of the West Indies, Mona, Jamaica

Tel +8764576990

Email paulbournel@yahoo.com
Background: Jamaica is a mid-range income developing country with an increasing population and public resource constraints. Therefore, reproductive health issues are of critical importance in Jamaica.

Aim: We examined the use of contraceptives among women and the factors that influence these women to use contraceptives.

Materials and method: In the current study we utilized the secondary dataset for the Reproductive Health Survey, conducted by the National Family Planning Board. The investigation was carried out with a stratified random sample of 7168 women aged between 15 and 49. The measures included demographic variables, method of contraception used, being in a relationship, number of partners, pregnancy status, and sexual activity status, along with other variables.

Results: The majority of participants used some method of contraception (64\%). The most popular method of contraception was a condom (32\%). Results of a multivariate analysis suggests that the explanatory variables for the method of contraception used are age $(\mathrm{OR}=0.98$, 95\% CI: $0.98-0.99)$, social class (OR $=0.83,95 \%$ CI: $0.73-0.95)$, being in a relationship $(\mathrm{OR}=3.35,95 \% \mathrm{CI}: 2.80-4.02)$, the rural-urban dichotomy $(\mathrm{OR}=1.16,95 \% \mathrm{CI}: 1.02-1.32)$, being currently pregnant $(\mathrm{OR}=0.01,95 \% \mathrm{CI}: 0.00-0.02)$, currently having sex $(\mathrm{OR}=2.29$, 95\% CI: $1.95-2.70)$, number of partners (OR $=1.85,95 \% \mathrm{CI}: 1.57-2.17)$, the age at which the women began using a contraceptive $(\mathrm{OR}=0.99,95 \% \mathrm{CI}: 0.98-1.00)$, and crowding $(\mathrm{OR}=1.40$, 95\% CI: 1.21-1.60).

Conclusion: The findings are far-reaching and can be of use for aid policy formulation and intervention.

Keywords: contraception, contraceptive methods, women, mid-range income, developing country

Our aim was to explore the use of contraceptives among women in Jamaica in order to correct a paucity of information in the academic literature, and to provide information for policy-makers, public health practitioners, and educators. The rationales influencing this research are (1) the lack of a comprehensive study on contraceptive use, and (2) the public health concerns which have arisen in the past decade. The mean age of first instance of sexual intercourse has been falling since 1997 and this is coupled with (1) increased contraceptive use, (2) increased teenage pregnancy, (3) increased premarital sexual relationships, and (4) increased HIV in the young adult population, as well as (5) the piecemeal approach to the study of contraceptive use in Jamaica. It should be noted that some adolescent and young adult females who engaged in unplanned sexual intercourse underestimated the risk of pregnancy and did not use contraceptives

submit your manuscript | www.dovepress.com 
consistently. The prevention of pregnancy was deemed to be the responsibility of the women. Their decision-making was strongly influenced by friends, family, and social norms. The most important forms of support these females received were from partners and parents. ${ }^{1}$ College women having their first experience of sexual intercourse did so at an older age than men. Some $61 \%$ of the women used an unreliable method or no contraceptive at all. The most frequent reason reported by these women for non-use of contraceptives in their first sexual intercourse was that it was unplanned. Lack of knowledge and inaccessible sources of contraception also influenced women's use of contraceptives. ${ }^{2}$

The use of contraceptives is also related to the length of birth intervals. A review of the literature connecting the length of birth interval to the use of contraceptives reveals mixed findings. However, the use of contraceptives is a protective factor against short birth intervals. ${ }^{3}$ The variables of the theories of planned behavior coupled with family planning self efficacy accounted for $65 \%$ of the outcome for intent to use oral contraceptives, and $27 \%$ of the variance in behavior among women. ${ }^{4}$ A study of women's views on family planning services suggests that they find several factors important. These are: the providers showing empathy and respecting women's autonomy, the provision of personalized care and comfort of the women, the information provided, the technical quality of care, and the organization of the service. Another important factor is the provider's ability and willingness to communicate in the language of the women. ${ }^{5}$ Moving from the clinic to their homes, the views of these women sometimes have little influence, even with the encouragement of their female friends. The encouragement wives receive from their social networks about the use of contraceptives does not influence the use of contraceptives by their husbands. ${ }^{6}$ However, some women who were experiencing domestic violence in their relationship with men stated that violence was not an important factor influencing their use of contraception. ${ }^{7}$

Illness also influences women's use of contraceptives. Women with bipolar disorder use contraception suboptimally. ${ }^{8}$ Similarly, women who are depressed are more likely to choose an ineffective method of contraception. These women need contraceptive counseling aimed at improving their decision-making and choice of contraception. ${ }^{9}$ A review of the studies dealing with oral contraceptives and multiple sclerosis (MS) suggests that the use of oral contraceptives does not increase the risk of MS. On the contrary, it may delay the onset of disease. ${ }^{10}$ Although knowledge of contraception is high among HIV sero-discordant couples, the use of contraceptives is low. Gender difference is an important factor, because many women engage in the clandestine use of contraceptives. ${ }^{11}$ The use of contraceptives among women is not only related to illness but also to religious factors. Religions differ on their dictates about contraception, which influences use among religious people shaped by the history and politics of their particular religion. ${ }^{12}$

Given the range of factors outlined above, when dealing with women's use of contraceptives, the promotion of reproductive health by the international donor community sometimes does not work. This failure occurs because the donor and the policy-makers of the target country define reproductive health differently. The priorities and values of the donors and policy-makers are at odds because cultural factors drive contraceptive use away from the expected outcome of the donors. ${ }^{13}$ The purpose of this study is to understand the methods of contraception used by Jamaican women, and some of the factors that influence them to use these methods of contraception.

\section{Methods}

Since 1997, the National Family Planning Board (NFPB) has been collecting information on women (aged between 15 and 49) in Jamaica regarding contraception usage and/or reproductive health. In 2002, the Reproductive Health Survey (RHS) collected data on women aged 15-49 and men aged 15-24. In the current study we extracted a sample of only women (age 15-49) given the nature of the research. The sample comprised 7168 women, representing a response rate of $91.8 \%$.

Stratified random sampling was used to design the frame from which the sample was drawn. Using the 2001 Census sector (or sampling frame), a 3-stage sampling design was used. Stage 1 involved the use of a selection frame of 659 enumeration areas (or enumeration districts, EDs). This was calculated based on probability proportion to size. Jamaica is classified into four health regions. Region 1 consists of Kingston, St Andrew, St Thomas, and St Catherine; Region 2 comprises Portland, St Mary, and St Ann; Region 3 is made up of Trelawny, St James, Hanover, and Westmoreland, with Region 4 covering St Elizabeth, Manchester, and Clarendon. The 2001 Census showed that region 1 comprised $46.5 \%$ of Jamaica, compared to Region 2 at $14.1 \%$, Region 3 at $17.6 \%$, and Region 4 at $21.8 \% .^{14}$

Stage 2 saw the clustering of households into primary sampling units (PSUs), with each PSU constituting an ED, which in turn consists of 80 households. The previous sampling frame was in need of updating, and so this was 
performed between January 2002 and May 2002. The new sampling frame forms the basis upon which the sampling size was computed for the interviewers to use. Stage 3 involved the final selection of one eligible female and male and this was done by the interviewer upon visiting the household.

The Statistical Institute of Jamaica (STATIN) provided the interviewers and supervisors, who were trained by McFarlane Consultancy to carry out the survey. The interviewers administered a 35 -page questionnaire. The data collection began on October 26, 2002 and was completed on May 9, 2003. The data were weighted in order to represent the population of women aged 15 to 49 in the nation. ${ }^{14}$

\section{Statistical methods}

We used the Statistical Packages for the Social Sciences (SPSS) for Windows, Version 16.0 (SPSS Inc; Chicago, IL, USA) for data analysis. Frequencies and means were computed on the basis of sociodemographic characteristics, health conditions, pregnancy, Pap smears, gynecological examinations, and reasons for choices. We also performed chi-square $\left(\chi^{2}\right)$ tests to compare associations for particular sociodemographic variables, contraception, pregnancy, and gynecological examination. Stepwise multiple logistic regressions were used to analyze factors that explained gynecological examinations undergone in the last 12-month period, and Pap smear tests done during the same period. Where collinearity existed $(R>0.7)$, variables were entered independently into the model to determine those that should be retained during the final model construction. ${ }^{15}$ To derive accurate tests of statistical significance, we used SUDDAN statistical software (Research Triangle Institute, Research Triangle Park, NC), and this was adjusted for the survey's complex sampling design.

\section{Measure}

Crowding is the total number of persons in a dwelling (excluding kitchen, bathroom, and verandah). Age is the number of years a person is alive up to his/her last birthday (in years). Contraceptive method was assessed using the question "Are you and your partner currently using a method of contraception?", and if the answer was yes "Which method of contraception do you use?" Age at which the individual began using contraception was assessed using the question "How old were you when you first used contraception?" Area of residence was assessed by "In which area do you reside?" The options were rural, semiurban, and urban. Currently having sex was measured using "Have you had sexual intercourse in the last 30 days?" Education was measured based on the question "How many years did you attend school?" Marital status was measured using the following question "Are you legally married now?", "Are you living with a common-law partner now? (that is, are you living as man and wife now with a partner to whom you are not legally married?)", "Do you have a sexual partner, that is, a more or less steady partner with whom you have sexual relations?", and "Are you currently single?" Age at first sexual intercourse was measured from "At what age did you first have sexual intercourse?" Gynecological examination was taken from "Have you ever had a gynecological examination?" Pregnancy was assessed by “Are you pregnant now?" Religiosity was evaluated from the question "With what frequency do you attend religious services?" The options range from at least once per week to only on special occasions (such as weddings, funerals, or christenings). Subjective social class was measured using the question "To which social class do you belong?" The options are lower, middle, or upper social hierarchy.

\section{Analytic model}

Using logistic regression, in this study we sought to examine factors associated with the method of contraception usage among women in Jamaica. Different social factors influence women's choices and their decision to use a method of contraception, and in this study we used Grossman's model ${ }^{16}$ which involves the use of econometric analysis to determine the use of health demand. Grossman's model has been modified and used by many scholars to examine health, health outcomes, and other health-related issues.

In the current research the theoretical framework of Grossman's econometric analysis was used to examine factors associated with the method of contraception usage among women aged 15-49 years in Jamaica. The variables used in this econometric model are based on relevant literature as well as the dataset. We will test the hypothesis that the methods of contraception usage among women aged 15-49 years are determined by particular sociodemographic variables (Equation [1]).

$$
\begin{aligned}
C_{w i}= & f\left(A_{i}, E D_{i}, U_{i}, S S_{i}, A R_{i}, P_{i}, F_{i}, G N_{i},\right. \\
& \left.A S_{i}, S_{i}, N_{i}, R_{i}, K_{i}, M_{i}, W_{i}, T_{i}, \varepsilon_{i}\right)
\end{aligned}
$$

where $C_{w i}$ denotes method of conception usage, $A_{i \text { is }}$ age, $E D_{i}$ represents educational level, $U_{i}$ means employment status, $S S_{i}$ is social class, $A R_{i}$ indicates area of residence, $P_{i}$ denotes current pregnancy status, $F_{i}$ is forced to have sex, $G N_{i}$ means gynecological examination in the last 12 months, $A S_{i}$ is age of first instance of sexual intercourse, $S_{i}$ represents currently having sex, $N_{i}$ is number of sexual partners of woman, $R_{i}$ denotes religiosity, $K_{i}$ currently in a sexual union, $M_{i}$ 
denotes age of first menstruation, $W_{i}$ represents crowding in household, $T_{i}$ denotes age at which contraceptive use began, and the parameter $\varepsilon_{i}$ is the model's error term.

Using the data to test the hypothesis (Equation [1]), from the logistic regression analyses, we can write equation [2] to represent the function that explains the method of contraception for women aged 15-49 years in Jamaica.

$$
C_{w i}=f\left(A_{i}, S S_{i}, A R_{i}, P_{i}, K_{i}, W_{i}, N_{i}, S_{i}, T_{i}, \varepsilon_{i}\right)
$$

To make more sense of the function (Equation [2]), we rewrote it into a new equation (Equation [3]):

$$
\begin{aligned}
\log (P / 1-P)= & \alpha+\beta_{1} A_{i}+\beta_{2} S S_{i}+\beta_{3} A R_{i}+\beta_{4} P_{i}+\beta_{5} K_{i} \\
& +\beta_{6} W_{i}+\beta_{7} N_{i}+\beta_{8}+\beta_{9} S_{i}+\beta_{10} T_{i}+\varepsilon_{i}
\end{aligned}
$$

where $P$ denotes the probability of currently using a method of contraception and $1-P$ is the probability of currently not using a method of contraception, $\alpha$ represents the constant,

\begin{tabular}{|c|c|c|}
\hline Characteristic & $\mathbf{n}$ & $\%$ \\
\hline \multicolumn{3}{|l|}{ Religiosity } \\
\hline At least once a week & 2707 & 37.8 \\
\hline At least once a month & 1368 & 19.1 \\
\hline Less than once a month & 861 & 12.0 \\
\hline Only on special occasions (weddings, funerals, christening) & 1631 & 22.7 \\
\hline Does not attend at all & 524 & 7.3 \\
\hline No response & 77 & I.I \\
\hline \multicolumn{3}{|l|}{ Marital status } \\
\hline Legally married & 1542 & 21.5 \\
\hline Common-law & 1733 & 24.2 \\
\hline Visiting & 1959 & 27.3 \\
\hline Not currently in union & 1934 & 27.0 \\
\hline \multicolumn{3}{|l|}{ Currently pregnant } \\
\hline Yes & 288 & 4.4 \\
\hline No & 6219 & 94.6 \\
\hline \multicolumn{3}{|l|}{ Ever been pregnant } \\
\hline Yes & 5301 & 84.3 \\
\hline No & 985 & 15.7 \\
\hline \multicolumn{3}{|l|}{ Forced to have sex } \\
\hline Yes & 747 & 11.6 \\
\hline No & 5707 & 88.4 \\
\hline \multicolumn{3}{|l|}{ Currently having sex (in the last 30 days) } \\
\hline Yes & 4289 & 59.8 \\
\hline No & 2879 & 40.2 \\
\hline \multicolumn{3}{|l|}{ Currently using a method of contraception } \\
\hline Yes & 4027 & 63.8 \\
\hline No & 2282 & 36.2 \\
\hline \multicolumn{3}{|l|}{ Employment status } \\
\hline Unemployed & $4 \mid 43$ & 57.8 \\
\hline Employed & 3025 & 42.2 \\
\hline \multicolumn{3}{|l|}{ Are of residence } \\
\hline Urban & 1144 & 16.0 \\
\hline Semi-urban & 2079 & 29.0 \\
\hline Rural & 3945 & 55.0 \\
\hline \multicolumn{3}{|l|}{ Socioeconomic class } \\
\hline Lower & 1705 & 23.8 \\
\hline Middle & 3079 & 43.0 \\
\hline Upper & 2384 & 33.2 \\
\hline Number of pregnancies that resulted in live births median (range) & & $2.0(0,14)$ \\
\hline Years of schooling mean (SD) & & 13.0 years ( 3.0 years) \\
\hline Age mean $(S D)$ & \multirow{2}{*}{\multicolumn{2}{|c|}{$\begin{array}{r}31.3 \text { years }(9.3 \text { years }) \\
17.0(\mid 5,49), \text { mean }=15.2 \text { yrs }(S D=5.8)\end{array}$}} \\
\hline Age of first sexual intercourse median (range) & & \\
\hline
\end{tabular}
$\beta_{1-10}$ means the coefficient of each variable from 1 to 10 .

Table I Sociodemographic characteristic of sample, $(\mathrm{N}=7168)$

Abbreviation: SD, standard deviation. 
The predictive power of the model was tested using the 'omnibus test of model' and Hosmer and Lemeshow's ${ }^{17}$ technique was used to examine the model's goodness of fit.

\section{Results}

Table 1 presents sociodemographic information on the sample. The sample comprised 7168 women aged 15 to 49 , and most of them were currently using a method of contraception (64\%). Currently, $4.4 \%$ of the sample were pregnant and $84.3 \%$ had previously been pregnant. Almost $16 \%$ had had at least one miscarriage, $2.2 \%$ at least one abortion, and $5.4 \%$ at least one stillbirth. The mean age of the sample was 31.0 years $(S D=9.3)$. A detailed description of the age cohort of the sample revealed that $13.8 \%$ of the women were $15-19$ years; $13.1 \%$ were aged $20-24 ; 16.4 \%$ were aged $25-29$ years; $18.3 \%$ were aged $30-34$ years; $16.2 \%$ were aged $35-39 ; 12.8 \%$ were aged $40-44$ years; and $9.4 \%$ were aged 45-49 years. Half of the sample began using a method of contraception at 19 years of age (range $=33$ years: $11,44)$, and $4.5 \%$ indicated that they desire to be pregnant sometime in the future.

Almost $62 \%$ of the respondents indicated that they had asked their partners to use a condom; of these, $20.1 \%$ of the women reported that they refused to do so. On the other hand, $5 \%$ of women said that they insisted that their partners did not use a condom during sexual intercourse. Twenty-three percent of the respondents indicated that they had had multiple partners. Of those with non-steady partners, $24 \%$ provided information on the frequency of use of condoms with these person/s: $49 \%$ indicated that they always used a condom, $26.1 \%$ used one most times, $0.7 \%$ seldomly used one, and $23.9 \%$ never did. Regarding women with a steady partner, $44.4 \%$ indicated that they always used a condom with their partners, $48 \%$ did most times, $6.0 \%$ seldomly did so, and $0.2 \%$ reported that they had never done so. Only $2.4 \%$ of the women in the sample were sex workers (being paid for sex; offering money or goods in exchange for sex), and $9.1 \%$ said that they had done this more than two times in their lives. Twenty-six percent of the sex workers indicated that they began while they were in school, and 57\% said they commenced after leaving school.

When the respondents were asked "Are you and your partner currently using a method of contraception or doing something to prevent pregnancy", $63.8 \%$ indicated yes. Of those who responded positively to use of a method of contraception, it was revealed that most respondents used a condom (62\%) followed by the pill (14.4\%), female tubal ligation (10.4\%), and injection (10\%). This question was followed by "Are you and your partner also using a second method of contraception", to which $14.6 \%$ indicated yes. The methods were withdrawal $(65.3 \%)$, rhythm, calendar or Billings (26.5\%), pill (2.1\%), diaphragm (4.1\%), or other $(2.0 \%)$. When the sample was asked "Are you and your partner also using a second method at the same time for either sexually transmitted disease prevention or contraception", $14.6 \%$ indicated yes. The methods were withdrawal (65.3\%), condoms (7.5\%), and other.

Table 2 contains information on particular demographic characteristics of the sample by age group.

Table 3 contains information on frequency of condom use (with nonsteady partner) by age group.

Table 4 contains information on frequency of condom use (with a steady partner) by age group.

\section{Multivariate analyses}

Table 5 contains information on factors that explain the method of contraception usage of women aged 15 to 49 . Using stepwise logistic regression analyses, eight variables emerged as statistically significant variables of women aged 15-49 who were currently using a method of contraception. Women (aged 15-49) in the upper social class were 17\% less likely to use a method of contraception in comparison with those in the lower class (OR $=0.83,95 \%$ CI: $0.73-0.95$. Older the women are $2 \%$ less likely to use a method of contraception $(\mathrm{OR}=0.98,95 \%$ CI: 0.98-0.99), and if they are pregnant they are $99 \%$ less likely to use a method of contraception. The model had statistically significant predictive power $\left(\right.$ model $\chi^{2}(\mathrm{df}=9)=1684.75, P$ value $<0.0001 ;$ Hosmer and Lemeshow goodness of fit $\chi^{2}=2.87, P=0.94$ ), and correctly classified $78.5 \%$ of the sample (Table 5).

\section{Study limitations}

One of the fundamental limitations in this study is the cross-sectional nature of the data collection. A crosssectional study cannot be used to establish causality or predictability, and the results can change over time. Hence, although social policy formulation relies on this research design, policy-makers should be cognizant of the aforementioned issues in designing interventions and strategic frameworks. Despite those limitations, cross-sectional data design is still a good way to collect social science data on a population.

\section{Discussion}

In the current study we found that although $64 \%$ of the sample indicated that they or their partner used a method of contraception, consistency of use among those with a 


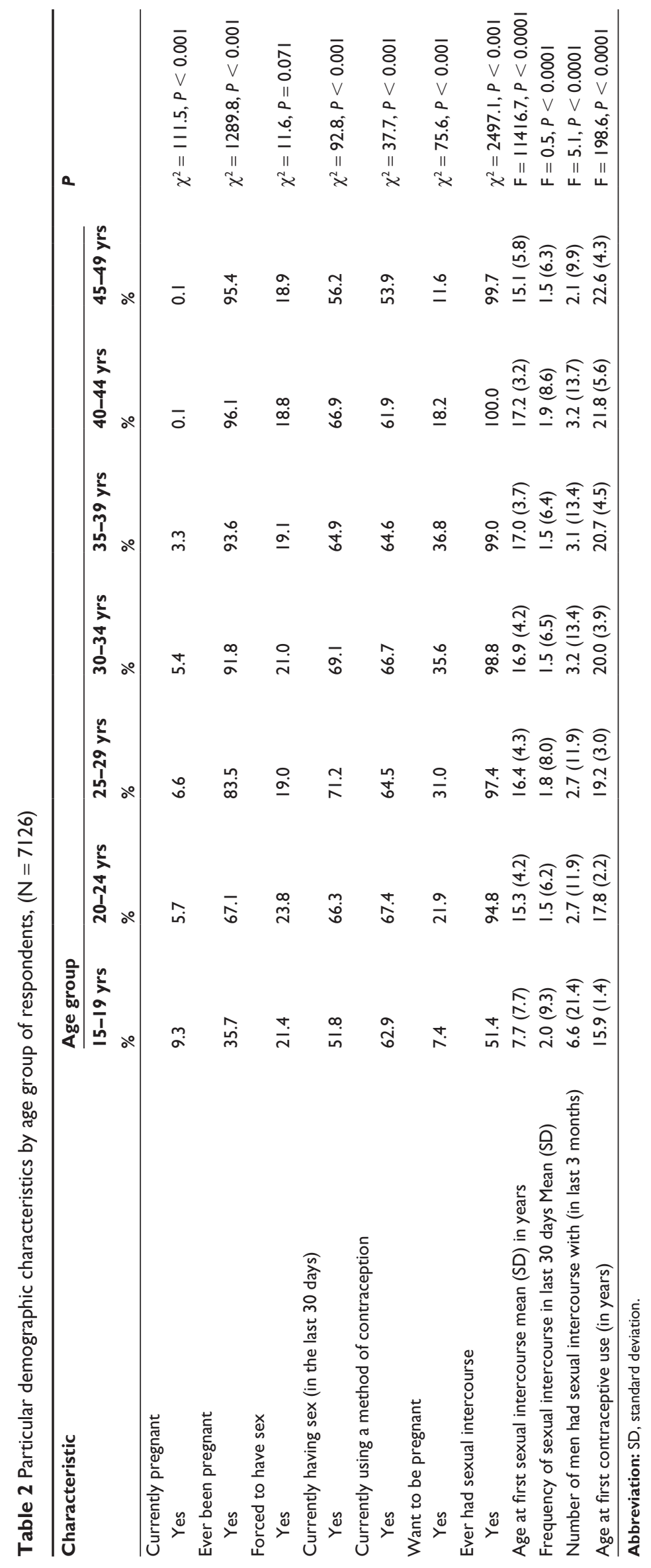


Table 3 Frequency of condom use (with non-steady partner) by age group, $N=1748$

\begin{tabular}{|c|c|c|c|c|c|c|c|c|}
\hline \multirow{3}{*}{$\begin{array}{l}\text { Frequency of } \\
\text { condom usage }\end{array}$} & \multicolumn{7}{|l|}{ Age group } & \multirow[t]{3}{*}{ Total } \\
\hline & $15-19$ yrs & $20-24$ yrs & $25-29$ yrs & 30-34 yrs & $35-39$ yrs & $40-44$ yrs & 45-49 yrs & \\
\hline & $\%$ & $\%$ & $\%$ & $\%$ & $\%$ & $\%$ & $\%$ & \\
\hline Always & 11.8 & 13.6 & 14.9 & 14.2 & 10.5 & 12.0 & 9.4 & 12.9 \\
\hline Most of the time & 7.0 & 9.6 & 6.5 & 5.3 & 4.9 & 6.9 & 8.2 & 6.8 \\
\hline Seldom & 0.0 & 0.3 & 0.0 & 0.6 & 0.0 & 0.0 & 0.0 & 0.2 \\
\hline Never & 3.9 & 6.3 & 5.9 & 6.5 & 7.9 & 6.3 & 7.1 & 6.2 \\
\hline $\begin{array}{l}\text { Never had non- } \\
\text { steady partner }\end{array}$ & 77.3 & 70.2 & 72.8 & 73.4 & 76.7 & 74.9 & 75.3 & 73.9 \\
\hline Total, n & 229 & 332 & 323 & 338 & 266 & 175 & 85 & 1748 \\
\hline
\end{tabular}

Notes: $\chi^{2}=20.9, P=0.644$.

steady partner was relatively low (always, $44.4 \%$; most times, $48.0 \%$ ) and $73.9 \%$ of the respondents indicated that they had never had a non-steady partner. Of those who had a non-steady partner, $49.3 \%$ consistently used a condom and $23.9 \%$ indicated that they had never used a condom. Almost $60 \%$ of the respondents indicated that they had had sex in the last 30 days, and $58 \%$ were primarily financially supported by their partner(s). Some $5 \%$ of the respondents stated that they desire to become pregnant. Current methods of contraception used by the female or her partner were explained by age of respondent, subjective social class, whether or not they were in a sexual union, area of residence, current pregnancy status, currently having sex (in the last 30 days), number of sexual partners, age at which individual began using contraception, and crowding.

In 1997, statistics revealed that the prevalence of women currently using contraceptives in Jamaica was $50.3 \%{ }^{21}$ and this increased to $64 \%$ in 2007 . The majority of women reported using a contraceptive, which is a very high rate of usage for a developing country. Using data from Kenya, Tanzania, and Trinidad and Tobago, Norman ${ }^{22}$ found that only $19 \%$ reported consistently using a condom. In another research, using a sample of 212 respondents from clinics in Montego Bay (Jamaica) who had sexually transmitted infections ${ }^{23}$ it was found that $43 \%$ reported using a condom the last time they had sexual intercourse. The current study revealed a higher consistency prevalence of condom usage than the aforementioned studies, and showed that almost 92.4\% of Jamaican women used a condom most times with their current partner, and $75.4 \%$ did so with non-steady partner(s).

Our results indicate that $21.4 \%$ of young women (aged 15-19) were forced into having sexual relations, $7.4 \%$ of adolescents (aged 15-19) desired to become pregnant, 51.4\% had sexual intercourse, some of them were having it twice a month, and on average they were having sex with 6.6 men in 90 days. Although the mean age of the first sexual intercourse was 15.2 years, the mean age of the first sexual intercourse for women between the ages of 15-19 years was 7.7 years of age. Furthermore, $35.7 \%$ of women between the ages of 15-19 years had been pregnant in the past. The present results showed that 1 in every 2 Jamaican woman between the ages of 15-19 years had had sexual intercourse in the last 30 days, and that 8 out of every 10 had been pregnant.

Some $21.5 \%$ of these women reported experiencing a miscarriage and stillbirth, with $2.2 \%$ of them having at least one abortion. This low rate of abortion reported is consistent with the relatively high use of contraceptives reported by the women, and the $62 \%$ of the respondents who declared that they asked their partner to use a condom. Taking the

Table 4 Frequency of condom use (with steady partner) by age group, $\mathrm{N}=1767$

\begin{tabular}{|c|c|c|c|c|c|c|c|c|}
\hline \multirow{3}{*}{$\begin{array}{l}\text { Frequency of } \\
\text { condom use }\end{array}$} & \multicolumn{7}{|l|}{ Age group } & \multirow[t]{3}{*}{ Total } \\
\hline & $15-19$ yrs & $20-24$ yrs & $25-29$ yrs & $30-34$ yrs & $35-39$ yrs & $40-44$ yrs & $45-49$ yrs & \\
\hline & $\%$ & $\%$ & $\%$ & $\%$ & $\%$ & $\%$ & $\%$ & \\
\hline Always & 49.4 & 38.9 & 41.5 & 42.0 & 43.2 & 54.2 & 55.8 & 44.4 \\
\hline Most of the time & 43.7 & 54.2 & 49.5 & 48.7 & 50.9 & 38.5 & 38.4 & 48.0 \\
\hline Seldom & 2.6 & 5.7 & 8.7 & 8.5 & 5.1 & 6.7 & 5.8 & 6.4 \\
\hline Never & 0.0 & 0.3 & 0.0 & 0.3 & 0.4 & 0.0 & 0.0 & 0.2 \\
\hline $\begin{array}{l}\text { Never had a non- } \\
\text { steady partner }\end{array}$ & 4.3 & 0.9 & 0.3 & 0.6 & 0.4 & 0.6 & 0.0 & 1.0 \\
\hline Total, $n$ & 231 & 332 & 323 & 343 & 273 & 179 & 86 & 1767 \\
\hline
\end{tabular}

Notes: $\chi^{2}=63.6, P<0.0001$. 
Table 5 Logistic regression: Explanatory variables on method of contraception usage of women (aged 15-49) in Jamaica, $n=6043$

\begin{tabular}{|c|c|c|c|}
\hline Explanatory variable & Odds ratio & $\mathrm{Cl}(95 \%)$ & $R^{2}$ \\
\hline Age & $0.98^{\text {kik }}$ & $0.98-0.99$ & 0.006 \\
\hline Lower class (reference group) & 1.00 & & \\
\hline Upper class & $0.83^{\text {wk }}$ & $0.73-0.95$ & 0.002 \\
\hline In union & $3.35^{\text {solok }}$ & $2.80-4.02$ & 0.158 \\
\hline Urban (reference group) & 1.00 & & \\
\hline Rural & $1.16^{*}$ & $1.02-1.32$ & 0.001 \\
\hline Currently pregnant & $0.01^{* 0+0 \% k}$ & $0.00-0.02$ & 0.114 \\
\hline Currently having sex & $2.29^{* * * *}$ & $1.95-2.70$ & 0.034 \\
\hline Number of partners & $1.85^{* k+k}$ & $1.57-2.17$ & 0.036 \\
\hline Age at which began using contraception & $0.99^{\text {*k }}$ & $0.98-1.00$ & 0.002 \\
\hline Crowding & $1.4^{* * k}$ & $1.21-1.60$ & 0.005 \\
\hline
\end{tabular}

Notes: 2 Log likelihood $=5588.0 . \mathrm{R}^{2}=0.358$. Model $\chi^{2}(\mathrm{df}=9)=1684.75 . P$ value $<0.0001$. Overall correct classification $=78.5 \%$. Correct classification of cases currently using a method of contraception $=91.8 \%$. Correct classification of cases not currently using a method of contraception $=54.2 \%$. " $P<0.05,{ }^{\text {"wn }} P<0.01$, ${ }^{x+a t} P<0.001$

possibility of under-reporting into account, the reported low use of abortion as a method of contraception contradicts recent media reports of widespread abortion in Jamaica, and the fierce activism of the church lobby against legalizing abortion. The assertiveness of the women in asking their men to use a condom is something that should be further encouraged within the national family planning strategy, rather than joining the moral panic against abortion that sometimes infuses national discussions of family planning. The reality which emerged from the current research is that a little over $50 \%$ of women are mostly supported financially by their partners, which means that the males are still able to determine, or veto, contraceptive usage. This is not particular to Jamaica as it was also found to be the case in sub-Saharan Africa, and the removal of spousal authorization (male) was associated with increased contraceptive usage. ${ }^{24}$

Despite the relatively high level of use of contraceptives among the women, what emerged from the current work gives rise to many public health and other concerns. Women as young as 7 years of age are having sexual intercourse, and 21 out of every 100 adolescents between the ages of 15 and 19 are forced into sexual activities. It does not cease there, as 36 out of every 100 young women (aged 15-19 years) have been pregnant, which means that there would be a high fertility rate or prevalence of adoption among these individuals. A number of young adult women in Jamaica were not only having premarital sexual relations, but they were having sexual intercourse with multiple partners. There is currently a public health problem as adolescents (aged 15-19) had more multiple sexual partners in the last 3 months than other women, with some young women engaging in promiscuity. This concurs with the literature which shows high promiscuity, premarital sexual activity, and high fertility among young adults. ${ }^{25-27}$

Less than $50 \%$ of the women with multiple partners who responded to the question about condom use indicated that they always used a condom. More than half of these participants did not use a condom with multiple partners, which increases their risk of contracting sexually transmitted infections (STIs). However, since only $24 \%$ of the women with multiple partners provided information about condom use, further research is required to explore this critically important health issue. Regarding women with one steady partner, only $44.4 \%$ stated that they always used a condom, which leaves them vulnerable to STIs if their male partner is unfaithful. Therefore, although the overall use of contraceptives among the women was relatively high (64\%), and $62 \%$ of the women asserted that their men used a condom, the breakdown of the data between women with steady and non-steady partners indicated that inconsistent condom use is high among Jamaican women. It is this inconsistent contraceptive usage, in particular condom utilization, that explains the HIV/AIDs epidemic in Jamaica and other developing countries. ${ }^{28-33}$

Only $56.1 \%$ of the sample stated their choice of contraceptives, among those who are currently using a method of contraception. Overall, the data suggest that among the women who responded about the method of contraception used, there is a greater concern for preventing an unwanted pregnancy than for contracting STIs. Only $32 \%$ of these women used a condom, with the remaining $68 \%$ using, in descending order of importance, the pill, injection, tubal ligation, the withdrawal method, IUD, the rhythm method, emergency contraceptives, implants, and other methods. More women aged 15-19 used a method of contraception to avoid being pregnant (64\%) than to prevent STIs (14.6\%), indicating that contraception is more about preventing pregnancy than preventing STIs. Embedded in this finding is the disconnection between awareness, knowledge, and practice.

Failure to consistently use a condom exposes sexually active individuals to HIV and/or STIs. It is clear from the current findings that women are exposing themselves to STIs by premarital sexual relations, promiscuity, and inconsistent condom usage. Young women are having sex as early as 7 years, and becoming pregnant between 15-19 years, which exposes many of these individuals to an HIV positive partner. HIV serodiscordant couples is a reality, as was noted by USAID and other scholars. ${ }^{34-37}$ Economic challenges, and men's economic supremacy, are among the reasons why 
women's reproductive health issues can be vetoed by males. Embedded in these findings is an explanation of why condoms and other contraceptive methods are inconsistently used by both women and men, as this is often based on the decision of the male partner. Henry-Lee ${ }^{38}$ opined that $34 \%$ of pregnancies in Jamaica are planned, and that poverty retards information on contraceptives and its usage. Another researcher found that $80 \%$ of adolescent pregnancies ${ }^{39}$ were unplanned, which reemphasizes the heavy involvement of this age cohort in premarital sexual activities and sometimes promiscuity. The lack of material power and economic independence means that some women will find it extremely difficult to dictate and insist that their male partners have an HIV test, and that a condom is consistently used in sexual intercourse.

Warren et al opined that $40 \%$ of all females aged 14-24 and $61 \%$ of those who are sexually experienced have been pregnant. ${ }^{40}$ Warren and his colleagues' work was carried out in 1988 and the current research found that $56 \%$ of women of the same age had already been pregnant. Disaggregating the age cohort (15-24 years), in this work it was found that $67.1 \%$ of women aged 20-24 years and 35.7\% of those aged 15-19 years have already been pregnant. Despite the difference in years between 1988 and now, with increased knowledge, wider access to contraception, and increased public health education campaigns, the number of young adult women who having unplanned pregnancies is still higher than in 1988. The public health concern is not only with increased pregnancies among young women, but promiscuity, the increased incidence of $\mathrm{HIV},{ }^{28}$ the problems of inconsistent condom usage, and the disparity between the widespread knowledge of HIV and continued inconsistent condom usage. ${ }^{23,41}$

Women who are involved in a relationship are more likely to use a method of contraception. It is possible that these women are not ready to get pregnant or they believe their partner may not be ideal for them. Women in urban areas are more likely to use a method of contraception than rural women. It is possible that rural women may have a lower level of education, and there are not enough professional women in the rural areas compared to urban areas, or rural women may be influenced by the culture of having a lot of children to help with agricultural work, and children may be seen as retirement planning given the higher level of poverty in rural areas. ${ }^{18-20}$ Women currently having sex and those with multiple partners tend to use a method of contraception. It is possible that these women are not ready to have children. Similarly, there is a positive relationship between crowding and use of contraceptives. However, the younger the age at which the women start to use a method of contraceptive, the more likely it is that they are using one currently.
Clearly, Jamaica has been struggling with premarital sexual relations and adolescent pregnancy for many decades ${ }^{42}$ and this continues unabated. In contemporary Jamaica, the issues are old, but there are also some new ones. Added to the old issues are increased HIV prevalence among young adults, ${ }^{43}$ early sexual relations of women aged $15-19$ years, promiscuity among women aged 15-19 years, the prevalence of young women who are forced to have sexual relations, frequency of sexual relations in a 30-day period, and the percentage of women aged 15-39 years who want to become pregnant. Douglas ${ }^{44}$ opined that the major cause of mortality among women aged 15-44 years in the Caribbean is AIDS, and that 1 in every 50 Caribbean nationals was infected with HIV/AIDS.

There is no denying that inconsistent condom use accounts for high fertility, pregnancies, and HIV/AIDS infections in the Caribbean and Sub-Saharan African nations. Therefore, it is useful to encourage the early use of contraceptives, in particular the condom, as a second method among young women. In 2000, the Jamaican Ministry of Health used the Jamaica Reproductive Health Survey for 1997, among other data sources, to write a 'Strategic Framework for Reproductive Health Programme for 2000-2005'. ${ }^{44}$ New data indicate that the issues are more diverse than in 1997 and therefore a new policy framework is needed for 2005 and beyond. It is an absolute that consistent condom usage can stem the rise in teenage pregnancies, HIV/AIDS,${ }^{45}$ and abortions, and reduce sexually transmitted infections ${ }^{46}$ and the risk of transmission among young women and men in developing countries. Wilks et al's findings revealed that $97 \%$ of those in the lower social hierarchy have had sexual intercourse, compared to $96 \%$ of the middle class, and $95 \%$ of the upper social hierarchy; $60 \%$ of Jamaican students (aged $15+$ years) have had sexual relations, as have $99 \%$ of those with primary or lower education level (secondary, 93\%; post-secondary, 94\%). ${ }^{47}$ In addition to the aforementioned, the new findings should be used to effectively frame policies to address the new realities. A multifaceted approach must be taken to address the new realities in Jamaica, and this must include (1) an intervention programme to address the information needs of adolescents, and to make reproductive health services more young people-friendly (2) post-intervention surveys to assess the effectiveness of implemented measures, (3) a sensitization campaign against male supremacy in vetoing reproductive health choices of females, (4) identifying new areas for contraception inquiry, (5) formulation of an intact condom usage campaign, and (6) designing a program to financially empower those in the lower class, the disadvantaged, orphans, 
and young people, as well as to provide the same group with educational empowerment. A study conducted in Mexico City comprising a group of young females who had unplanned pregnancies emphasized the rational of financial empowerment in contraceptive decision. The respondents indicated that they leave contraceptive decisions to their partner as "he looks after me", ${ }^{48}$ indicating the male's vetoing power in reproductive health decisions; and the justification for their involvement in women's reproductive health matters.

\section{Conclusion}

The majority of participants used some method of contraception. The most popular method of contraception among the women was condoms. Despite the relatively high use of contraceptives among the women, a breakdown of the data on women in a steady relationship and women with multiple partners, suggests that $44 \%$ of the women used a condom in the former group and $49 \%$ used a condom in the latter group. These findings have implications for the spread of STIs. There are several explanatory variables for contraceptive use among the women. These explanatory factors are age, social class, being in a relationship, the rural-urban dichotomy, being currently pregnant, currently having sex, the number of partners, the age at which the women began using a contraceptive, and crowding.

\section{Disclaimer}

The authors would like to note that while this study used secondary data from the Reproductive Health Survey, none of the errors in this paper should be ascribed to the National Family Planning Board, but to the authors.

\section{Acknowledgments}

The authors thank the Data Bank in the Sir Arthur Lewis Institute of Social and Economic Studies at the University of the West Indies, Mona, Jamaica for making the dataset (Jamaica Survey of Living Conditions, 2002) available for use in this study, and the National Family Planning Board for commissioning the survey.

\section{Disclosures}

The authors report no conflicts of interest in this work.

\section{References}

1. Ekstrand M, Tyden T, Darj E, Larsson M. An illusion of power: Qualitative perspectives on abortion decision-making among teenage women in Sweden. Perspec Sexual Reprod Health. 2009;41:173-180.

2. Needle RH. The relationship between first sexual intercourse and ways of handling contraception among college students. $J$ Am Coll Health Assn. 1975;24:106-111.
3. Yeakey MP, Ramachandran DV, Myint Y, Creanga AA, Tsui AO. How contraceptive use affects birth intervals: results of a literature review. Stud Fam Plan. 2009;40:205-214.

4. Peyman N, Oakley D. Effective contraceptive use: an exploration of theory-based influences. Health Ed Res. 2009;24:575-585.

5. Becker D, Klassen AC, Koenig MA, LaVeist TA, Sonenstein FL, Tsui AO. Women's perspectives on family planning service quality: An exploration of difference by race, ethnicity and language. Perspec Sex Reprod Health. 2009;41:158-165.

6. Avogno W, Agadjanian V. Men's social networks and contraception in Ghana. J Biosoc Sci. 2008;40:413-429.

7. Ogunjuyiqbe Po, Akinlo A, Oni GO. Violence against women as a factor in unmet need for contraception in Southwest Nigeria. $J$ Fam Violence. 2010;25:123-130.

8. da Silva Magalhaes PV, Kapczinski F, Kauer-Sant'Anna M. Use of contraceptive methods among women treated for bipolar disorder. Arch Women Mental Health. 2009;12:183-185.

9. Garbers S, Correa N, Tobier N, Blust S, Chiasson MA. Association between symptoms of depression and contraceptive method choices among low income women at urban reproductive health centers. Maternal Child Health J. 2010;14910:102-109.

10. Alonso A, Clark CJ. Oral contraceptives and the risk of multiple sclerosis: a review of epidemiologic evidence. J Neuro Sci. 2009;286: $73-75$.

11. Grabbe K, Stephenson R, Vwalika B, et al. Knowledge, use, and concerns about contraceptive methods among sero-discordant couples Rwanda and Zambia. J Women Health. 2009;18:1449-1456.

12. Agadjanian V, Yabiku ST, Fawcett L. History, community milieu, and Christian-Muslim differentials in contraceptive use in Sub-Saharan Africa. J Sci Study Religion. 2009;48:462-479.

13. Waller KA. Understanding policymakers' perspectives. Diss Ab Int Sec B: Sci Eng. 2009;69:7452.

14. National Family Planning Board. Reproductive Health Survey, 2002 (Jamaica). Kingston, Jamacia: NFPB; 2005.

15. Polit DF. Data Analysis and Statistics for Nursing Research. Stamford, CT: Appleton and Lange Publisher; 1996.

16. Grossman M. The demand for health - a theoretical and empirical investigation. New York, NY. National Bureau of Economic Research; 1972.

17. Homer D, Lemeshow S. Applied logistic regression, 2nd ed. New York, NY: Wiley; 2000.

18. Planning Institute of Jamaica, (PIOJ), Statistical Institute of Jamaica, (STATIN). Jamaica Survey of Living Conditions, 1989-2007. Kingston, Jamacia: PIOJ, STATIN; 1989-2008.

19. Statistical Institute of Jamaica (STATIN). Demographic Statistics, 1988-2007. Kingston, Jamaica; STATIN; 1989-2008.

20. Planning Institute of Jamaica (PIOJ). Economic and Social Survey of Jamaica, 1990-2007. Kingston, Jamaica: PIOJ; 1991-2008.

21. National Family Planning Board (NFPB). Reproductive Health Survey 1997. Kingston, Jamaica: NFPB;1999.

22. Norman LR. Predictors of consistent condom use: a hierarchical analysis of adults from Kenya, Tanzania and Trinidad. Int J STD AIDS. 2003; 14:584-590.

23. Nnedu ON, McCorvey S, Campbell-Forrester S, et al. Factors influencing condom use among sexually transmitted infection clinic patients in Montego Bay, Jamaica. Open Reprod Sci J. 2008;1:45-50.

24. Cook RJ, Maine D. Spousal veto over family planning services. Am J Public Health. 1987;77:339-344.

25. Feyisetan B, Pebley AR. Premarital sexuality in urban Nigeria. Stud Fam Plan. 1989;20:343-354.

26. Hull TH, Hasmi E, Widyantoro N. Peer initiatives for adolescent reproductive health projects in Indonesia. Reprod Health Matters. 2004; 12:29-39.

27. Sychareun V. Meeting the contraceptive needs of unmarried young people: attitudes of formal and informal sector providers in Vietiane Municipality, Lao PDR. Reprod Health Matters. 2004; 12:155-165. 
28. Pan American Health Organization (PAHO). Health in the Americas, 2007 Volume II: Countries. Washington, DC: PAHO; 2007. pp. $448-464$.

29. Population Action International. A Measure of Survival. Calculating women's sexual and reproductive risk. Washington DC: Population Action International; 2007.

30. World Health Organization (WHO). World Health Statistics, 2009. Geneva, Switzerland: WHO; 2009.

31. Rawlins J, Crawford T. Women's health in the English-speaking Caribbean: the case of Trinidad and Tobago. J Soc Econ Stud. 2006; $55: 1-31$.

32. George C, Alary M, Otis J. Correlates of sexual activity and inconsistent condom use among high-school girls in Dominica. West Indian Med J. 2007;56:433-438.

33. Thomas, Tara. Youth Reproductive and Sexual Health in Jamaica. Washington: DC, Advocates for Youth; 2006.

34. USAID. HIV prevention knowledge base: Emerging areas. HIV prevention for serodiscordant couples. New York: USAID; 2009. Available from: http://www.aidstar-one.com/prevention/knowledgebase. Accessed May 1, 2010.

35. Bunnel R, Opio A, Musinguzi J, et al. HIV transmission risk behavior among HIV-infected adults in Uganda: results of nationally representative survey. AIDS. 2008;22:617-624.

36. Bunnel R, Nassozi J, Marum E, et al. Living with discordance: knowledge, challenges, and prevention strategies of HIV-discordant couples in Uganda. AIDS Care. 2005;17:999-1002.

37. Dunkle K, Stephenson R, Karita E, et al. New heterosexually transmitted HIV infections in married or cohabiting couples in urban Zambia and Rwanda: an analysis of survey and clinical data. Lancet. 2008;37: 2183-2191.
38. Henry-Lee A. Women's reasons for discontinuing contraceptive use within 12 months: Jamaica. Reprod Health Matters. 2001;9:213-220.

39. Crawford TV, McGrowder DA, Crawford A. Access to contraception by minors in Jamaica: a public health concern. North Am J Med Sci. 2009; 1:247-255.

40. Warren DP, Morris L, Jackson J, Hamilton P. Fertility and family planning among young adults in Jamaica. Int Fam Plan Persp. 1988;14: 137-141.

41. Duncan J, Gebre Y, Grant Y, et al. HIV prevalence and related behaviors among sex workers in Jamaica. Sex Trans Dis. 2010;37(5):306-310.

42. Drayton VLC. Contraceptive use among Jamaican teenage mothers. Rev Panam Salud Publica. 2002;11:150-157.

43. Douglas DL. Perspectives on HIV/AIDS in the Caribbean. In: Morgan O, editor. Health issues in the Caribbean. Kingston, Jamacia: Ian Randle; 2005. pp. xv-xxi.

44. Jamaican Ministry of Health $(\mathrm{MoH})$. Strategic framework for reproductive health within the Family Health programme 2000-2005. Kingston: $\mathrm{MoH} ; 2000$.

45. Steiner MJ, Cates W. Are condoms the answer to rising rates of nonHIV sexually transmitted infections? Yes. BMJ. 2008;336:184-185.

46. Carey RF, Lytle CD, Cyr WH. Implications of laboratory tests of condom integrity. Sex Trans Dis. 1999;26:216-220.

47. Wilks R, Younger N, Tulloch-Reid M, McFarlane S, Francis D. Jamaica Health and Lifestyle Survey 2007-2008. Kingston, Jamacia: Tropical Medicine Research Institute, University of the West Indies, Mona; 2008.

48. World Health Organization (WHO). Reproductive Health Research at WHO: A new beginning. Biennial Report 1998-1999. Geneva, Switzerland: WHO; 2000. p. 31.
Open Access Journal of Contraception

\section{Publish your work in this journal}

Open Access Journal of Contraception is an international, peerreviewed, open access, online journal, publishing original research, reports, reviews and commentaries on all areas of contraception. In addition to clinical research, demographics and health-related aspects, the journal welcomes new findings in animal and preclinical studies

\section{Dovepress}

relating to understanding the biological mechanisms and practical development of new contraceptive agents. The manuscript management system is completely online and includes a very quick and fair peer-review system. Visit http://www.dovepress.com/testimonials.php to read real quotes from published authors. 